\title{
The Gestural and Temporal Organisation of Assimilation
}

\author{
Sidney A. J. Wood \\ Department of Linguistics, University of Lund, Sweden
}

\begin{abstract}
Bulgarian apico-alveolar stops and Swedish dorsovelar stops are palatalized when adjacent to front vowels. An X-ray motion film study of these assimilations is presented here. Two issues are examined, extrinsic vs intrinsic production of assimilation and feature spreading vs. coproduction. The articulator gestures involved in these assimilations were initiated earlier, or were held longer, than in unassimilated situations. This revision of gesture timing in relation to adjacent activity indicates that these assimilations are preplanned and do not reflect coarticulation or vocal tract biodynamics. The timing and coordination of the articulature gestures involved in these assimilations is better described as coproduction than feature spreading. The X-ray motion films are part of an investigation of the temporal organisation of coarticulation and assimilation (Wood 1991, 1993, 1994, forthcoming)
\end{abstract}




\section{Preplanned activity and biodynamic accidents}

Since the 1960s it has been customary to distinguish between universal articulatory constraints and arbitrary language-specific speech habits (Wang and Fillmore 1961). The former were said to be intrinsic to the "speech mechanism" (i.e. the consequence of the biodynamics of the vocal tract), the latter were said to be extrinsic to the vocal tract (i.e. controlled from the brain). Many assumed assimilation to be an intrinsic process, often explained by Öhman's $(\underline{1966}, \underline{1967)}$ model of coarticulation. There, all phonemes are independent and the necessary motor commands for each were said to clash in the vocal tract. Palatalization, for example, is a perturbation due to a consonant articulation being superimposed on and summed with an independent tongue body activity for a front vowel. This contrasts with the hitherto widely held view of classical phoneticians since at least Sweet (1877) and Jespersen (1897) who saw assimilation as the result of preplanned reorganisation of the consonant target, i.e. a process that is extrinsic to vocal tract mechanics. 


\section{Assimilation}

Two rival processes are currently offered for assimilation: feature spreading and coproduction (Fowler 1980). With the feature spreading approach, inherited from classical phonetics and transformational phonology, the articulatory target of the assimilated phoneme is said to be changed by having the assimilating articulation incorporated into its own plan. With coproduction, the assimilating articulation is never actually copied to the assimilated phoneme; it remains the exclusive property of the assimilating phoneme and is stretched and produced simultaneously with the assimilated phoneme. 


\section{Procedures}

This poster reports examples of palatalized alveolars by a Bulgarian subject and palatalized velars by a Swedish subject.

The data was obtained from X-ray films by procedures described in Wood (1991, 1994). The films were made at 75 frames/sec (13.3 msecs per frame), with a $3 \mathrm{msec}$ exposure during each frame.

Background information on Bulgarian vowels is given in Pettersson and Wood (1987) and in Wood and Pettersson (1988).

Articulator movement was detected and recorded by comparing midsagittal profile tracings from one film frame to the next. The articulator gestures that are relevant for the assimilations reported here are four tongue body gestures relative to the mandible (palatal, velar, uvular and pharyngeal) as described in Wood (1979), and coronal elevation relative to the tongue body. 


\section{The Bulgarian and Swedish data}

Informant: adult male, Sofia

The Bulgarian utterance:

deteto xodi po pătishtata

/de'teto 'xodi 'po 'pătiftata/

[di'tetu 'xodi 'po 'petiftətə]

'the child was walking along the path'

\section{Consonant environments:}

Alveolar between palatals

Alveolar between nonpalatals

Alveolars between palatal and nonpalatal
Informant: Adult male, South Sweden

\section{The Swedish utterance:}

$$
\begin{aligned}
& \text { kacki kakor } \\
& \text { /'kaki 'ka:kur/ } \\
& \text { [,kaki 'ka:kuR] }
\end{aligned}
$$

a pair of nonsense words

\section{Consonant environments:}

Velar between nonpalatals

Velars between palatal and nonpalatal 


\section{Example 1: Bulgarian alveolars between nonpalatal and palatal}

\section{Articulatory profiles}

Two profiles from /t/ in /âti/

comparing the nonpalatalized implosion with the palatalized release

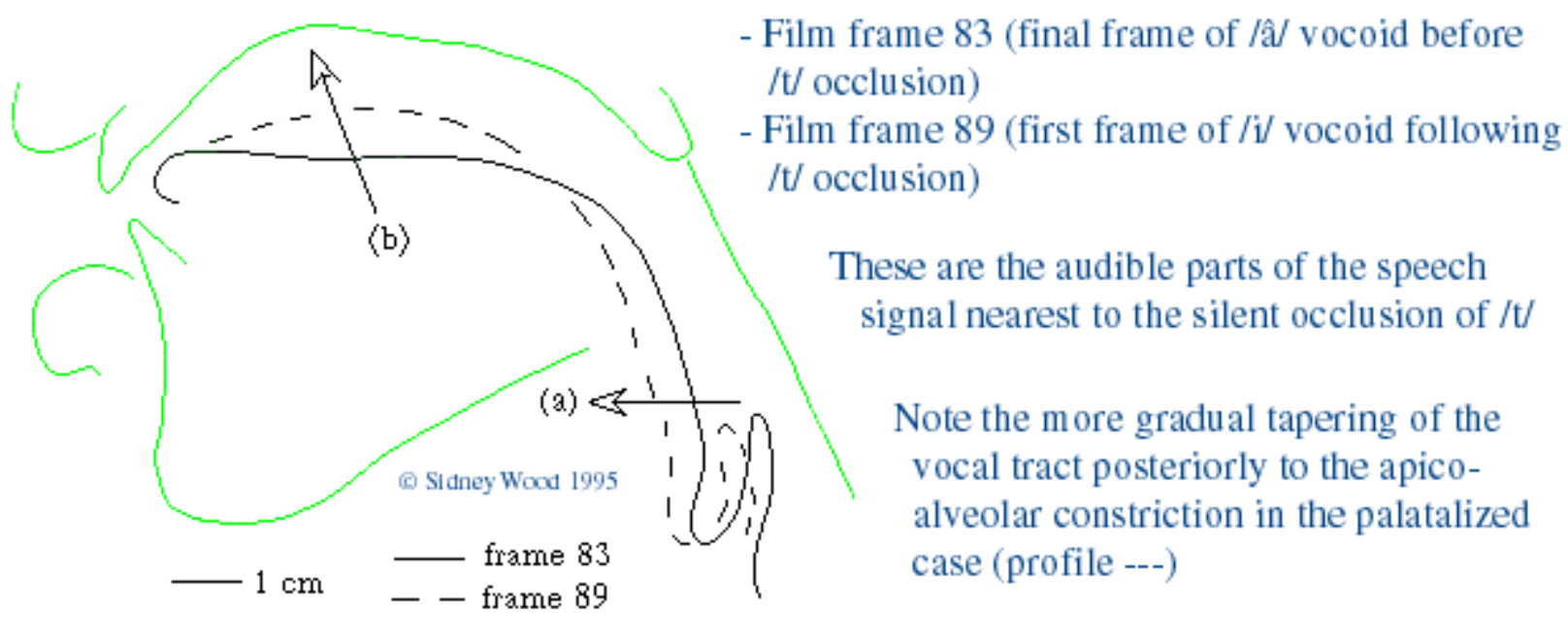

The difference between the two profiles represents unbroken tongue movement during the /t/ occlusion reflecting (a) continuing tongue body withdrawal of pharyngeal /â/ and (b) continuing tongue body approach of palatal/i/ 


\title{
Bulgarian alveolars between nonpalatal and palatal (contd.)
}

\author{
Gesture coordination
}

\section{Interweaving of articulator gestures for /âti/ (in pâtishtata)}

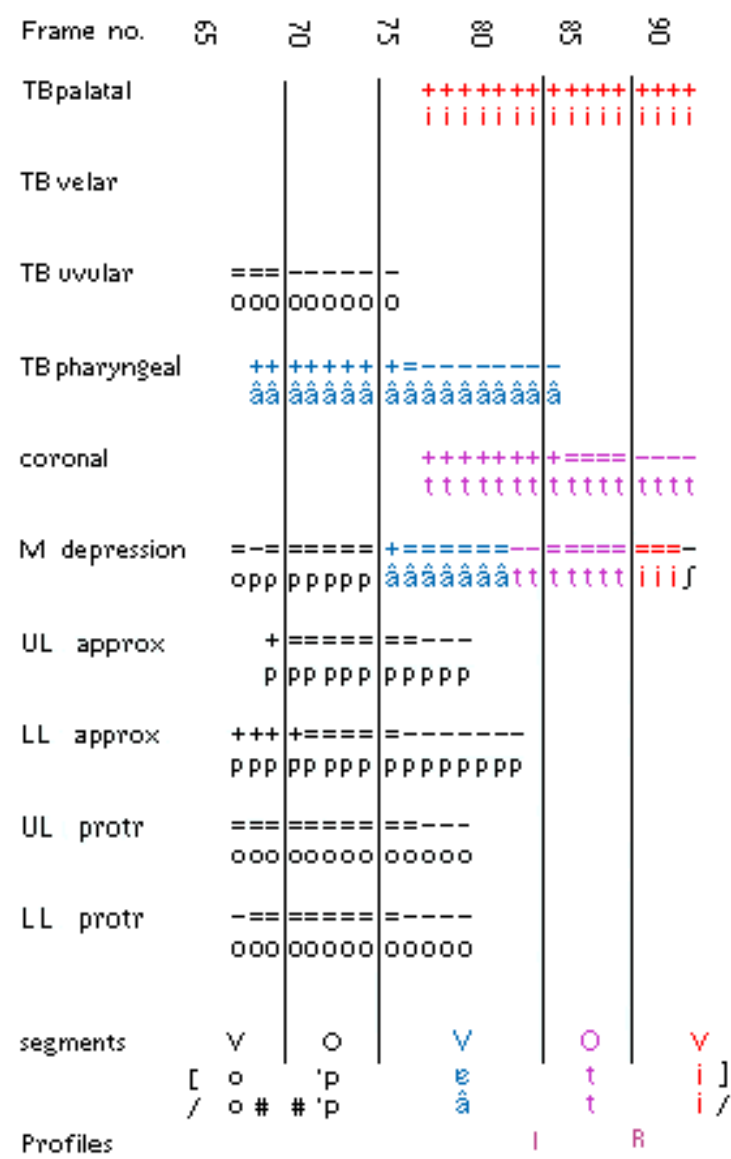

The articulator gestures are listed down the left, the film frames are numbered along the top

A row shows activity of the respective articulator. Each instance of a gesture is assigned to the phoneme the articulator happens to be busy with

A column shows all activity during the respective film frame. Coarticulation appears as simultaneous activity for different phonemes

+ Gesture approach (movement towards target)

= Gesture hold (no movement)

- Gesture withdrawl (movement from target)

V Phonetic vocoid segment in sound wave

O Phonetic occlusive segment in sound wave

I Frame 83, closure of /t/ at end of /â/ vocoid R Frame 89, release of / $t$ / at beginning of /i/ vocoid

The palatal tongue body approach of /i/ was initiated in frame 77 during the vocoid segment of /â/, continued through the occlusion of /t/ (frames 84-88), and was sufficiently advanced in frame 89 to palatalize the $/ t /$ release 


\section{Example 2: Bulgarian alveolars between palatal and nonpalatal}

\section{Articulatory profiles}

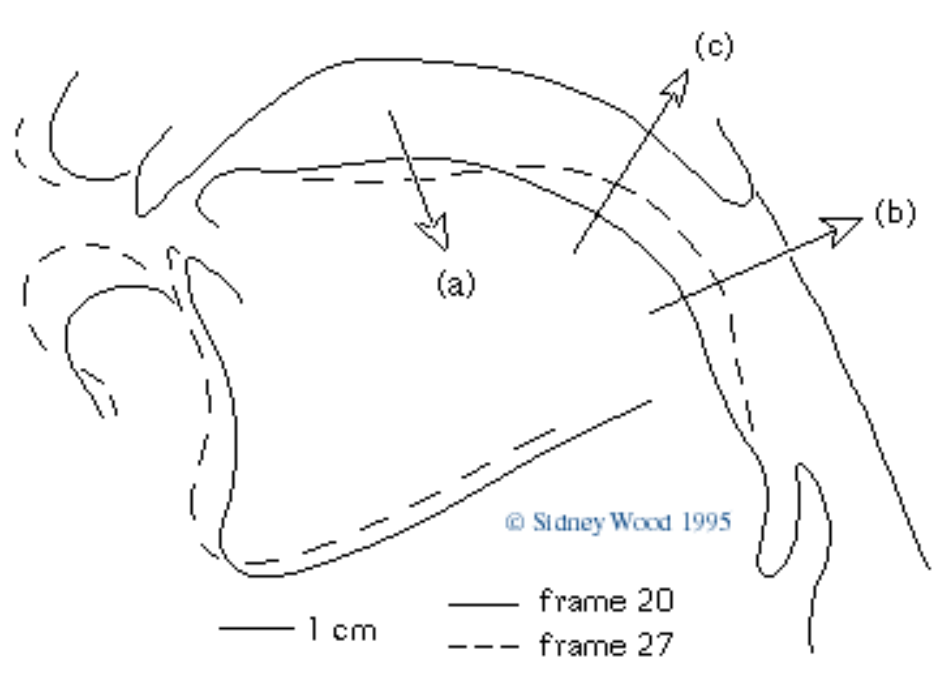

Two profiles from /t/ in /eto\#x/ com paring the palatalized closure (frame 20) with the nonpalatalized release (frame 27).

- Film frame 20: final frame of /e/ vocoid before / $t /$ occlusion - Film frame 27: first frame of $/ 0 /$ vocoid after/t/ occlusion

These are the audible parts of the speech signal nearest to the silent occlusion of $/ \mathrm{t} /$

Note the more gradual tapering of the vocal tract posteriorly to the apicoalveolar constriction in the palatalized case (profile —_)

The difference between the two profiles represents tongue movement during the / $t$ / occlusion due to (a) palatal tongue body withdrawal of $/ \mathrm{e} /$, (b) uvular tongue body approach of $/ 0 /$, and (c) velar tonguee body approach of $/ \mathrm{x} /$. 


\title{
Bulgarian alveolars between palatal and nonpalatal (contd.)
}

\author{
Gesture coordination
}

\section{Interweaving of articulator gestures for /eto/ (in deteto xodi)}

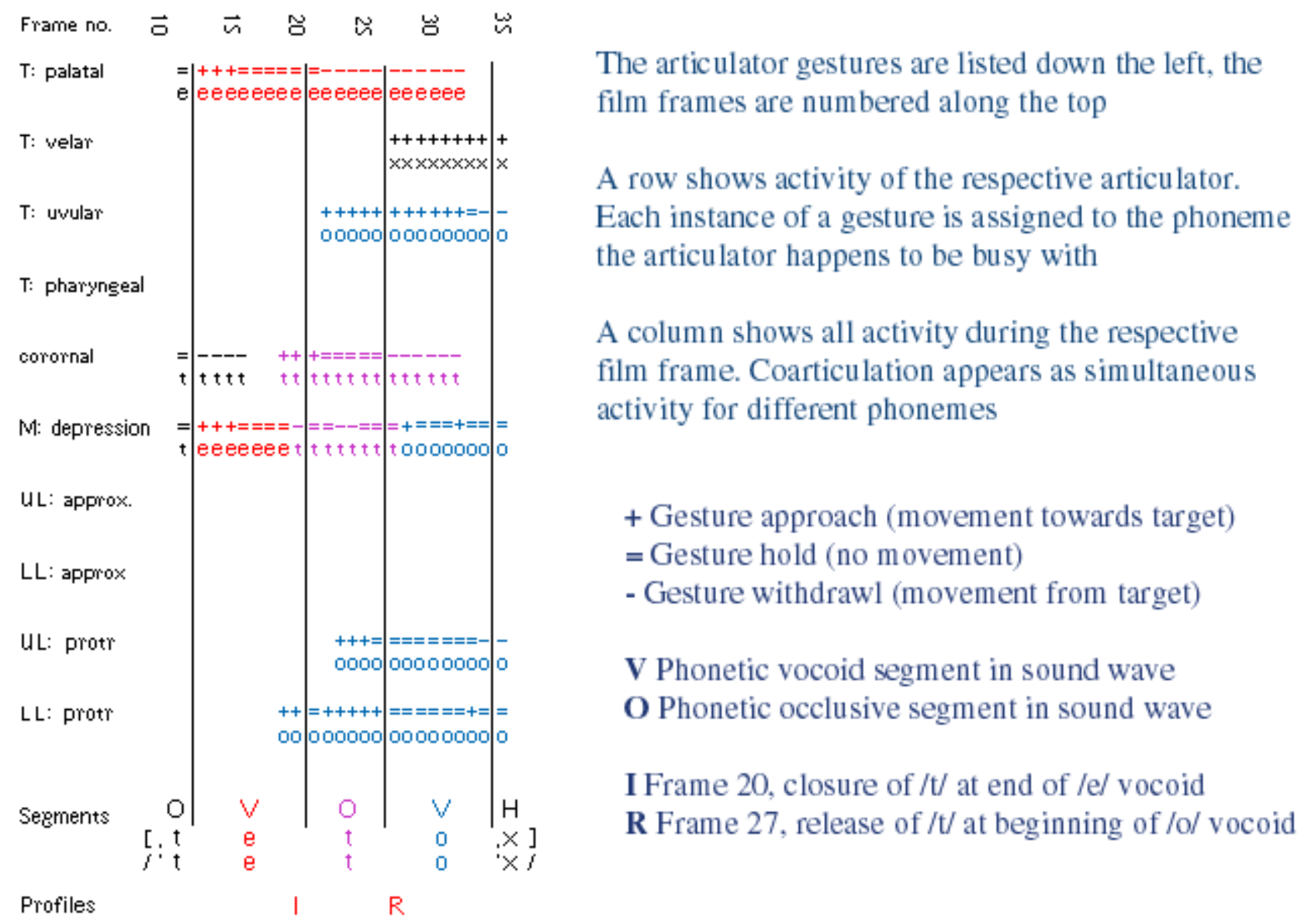

The palatal tongue body of /e/ was held through the latter part of the /e/ vocoid segment and into the /t/ occlusion, frames 16-21, palatalizing the closure

The uvular tongue body approach of $/ \mathrm{o} /$ was initiated in frame 22 during the $/ \mathrm{t} /$ occlusion, and had progressed so far by frame 27 that the $/ \mathrm{t} /$ release was not palatalized 


\section{Bulgarian alveolar stops: Discussion}

The instances of alveolar stops presented on the preceding pages were palatalized on the flank adjacent to a palatal vowel.

- The first example (comparing the closure and the release of /t/ in /ăti/ in pătishtata) showed a palatalized release:

- The second example, (comparing the closure and release of $/ \mathrm{t} / \mathrm{in} / \mathrm{eto} / \mathrm{in}$ deteto xodi) shows a palatalized closure.

What is interesting is the different timing of the articulator gestures for these two contextual situations.

For the palatalized release (example 1 p.7), the pharyngeal tongue body withdrawal of /ă/ (a) and the palatal tongue body approach of $/ \mathrm{i} /(\mathrm{a}, \mathrm{b})$ commenced as early as the pre-stop vocoid segment of $/ \mathrm{a} /$. They continued through the $/ \mathrm{t} /$ occlusion and had progressed sufficiently by the /t/ release to palatalize it. The palatal tongue body gesture was phased relative to the coronal gesture and laveolar occlusion in such a way that the $/ \mathrm{t} /$ release was palatalized but not the closure. This phasing of articulator gestures is typical of coproduction (with the palatal tongue body gesture of the post-stop vowel implemented simultaneously with the alveolar occlusion and timed to arrive at the stop release) rather than anticipatory feature spreading from the post-stop vowel to the alveolar stop (where the stop would get a palatal articulator gesture of its own duplicated from the vowel).

For the palatalized closure (example 2 p.9) the palatal tongue body gesture of pre-stop /e/ was held until the end of the vocoid segment and into the beginning of the occlusion. The palatalal tongue body withdrawl of /e/ (a) and the uvular tongue body approach of /o/ (b) did not commence until after the / $t /$ closure. This articulator phasing is also typical of coproduction but not of feature spreading. 


\section{Bulgarian alveolar stops: Discussion (contd.)}

The palatal tongue body gesture of a front vowel was thus phased in two different ways relative to the occlusion of an adjacent alveolar stop. To palatize the closure flank, the palatal posture of the pre-stop front vowel is held until the end of its vocoid segment before being withdrawn. To palatalize the release flank, the palatal tongue body approach of a post-stop front vowel is activated as early as the end of the preceding vocoid segment and continues during the alveolar occlusion in order to be in place at the release.

The palatal tongue body gesture of a front vowel is thus not only locked to its own vocoid segment, it is also locked to the appropriate flank of an adjacent alveolar stop. The two different phasings of the palatal tongue body gesture point to preplanning of this assimilation.

Fant (1960) reports X-ray and acoustic data on palatalization of Russian alveolars. There, the vocal tract is more narrowly tapered posteriorly to a palatalized alveolar occlusion, with consequently greater coupling of the turbulence source to high frequency back cavity resonances, producing a burst spectrum with more energy around 8-9000 Hz. The F2 locus is about $200 \mathrm{~Hz}$ higher than otherwise. Similar narrower tapering in the palatalized case can be seen in the two examples presented here. 


\section{Example 3: Swedish velars between nonpalatal and palatal}

\section{Articulatory profiles}

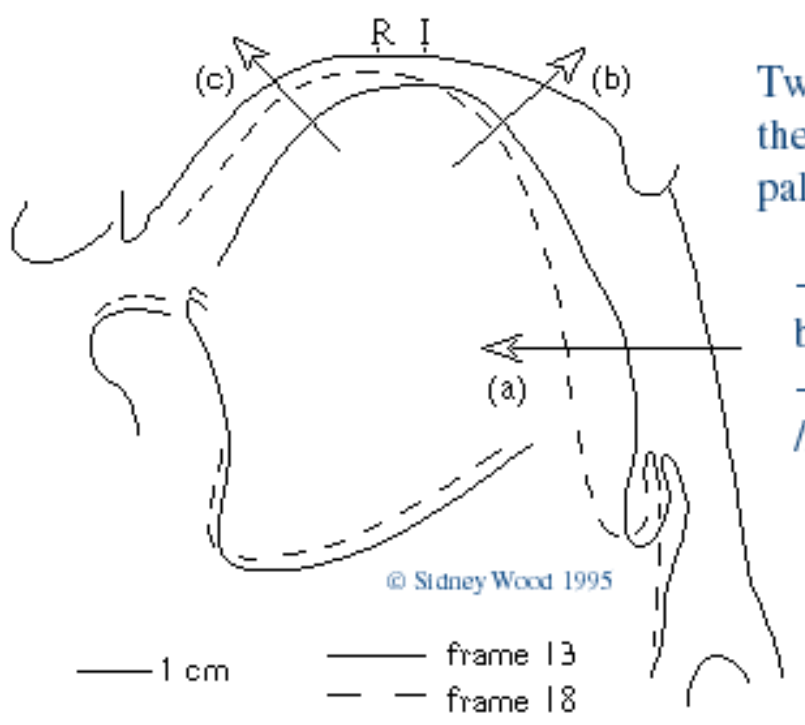

Two profiles from / $\mathrm{k} /$ in /aki/ (kacki), comparing the nonpalatalized closure (frame 13) with the palatalized release (frame 18)

- Film frame 13: final frame in $/ \mathrm{a} /$ vocoid before $/ \mathrm{k} /$ occlusion

- Film frame 18: first frame in /e/ vocoid after $/ \mathrm{k} /$ occlusion

These are the audible parts of the speech signal closest to the silent occlusion of $/ \mathrm{k} /$

The center of the linguopalatal contact shifted anteriorly from I to R during the occlusion

During the /a/ vocoid, the pharynx was widened by the pharyngeal tongue body withdrawal of $/ \mathrm{a} /$ (a) and the faucal passage narrowed by the velar tongue body approach of $/ \mathrm{k} /$ (b)

The difference between the two profiles represents tongue movement during the occlusion due to continued tongue body withdrawal of $/ \mathrm{a} /$ (a), velar tongue body withdrawal of $/ \mathrm{k} /$, and the palatal tongue body approach of /i/ (c) 


\title{
Swedish velars between nonpalatal and palatal (contd.)
}

\author{
Gesture coordination
}

\section{Interweaving of articulator gestures for /aki/ (in kaki)}

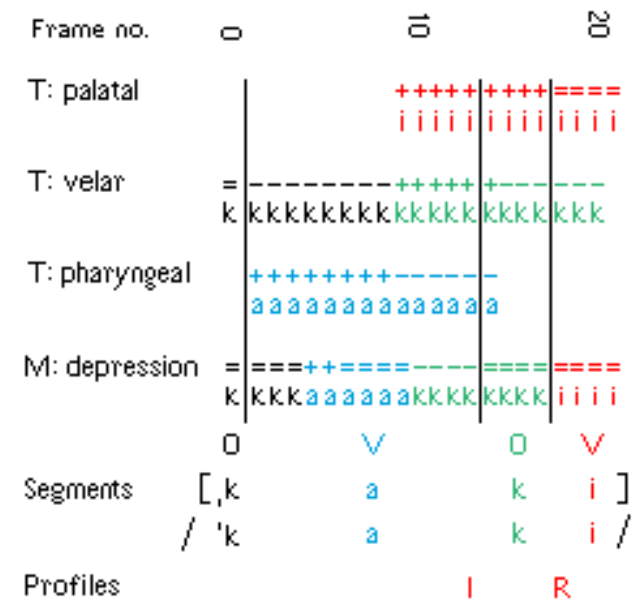

The articulator gestures are listed down the left, the film frames are numbered along the top

A row shows activity of the respective articulator. Each instance of a gesture is assigned to the phoneme the articulator happens to be busy with

A column shows all activity during the respective film frame. Coarticulation appears as simultaneous activity for different phonemes

+ Gesture approach (movement towards target)

= Gesture hold (no movement)

- Gesture withdrawl (movement from target)

V Phonetic vocoid segment in sound wave

O Phonetic occlusive segment in sound wave

I Frame 13 , closure of $/ \mathrm{k} /$ at end of $/ \mathrm{a} /$ vocoid

R Frame 18 , release of $/ \mathrm{k} /$ at beginning of $/ \mathrm{i} /$ vocoid

The palatal tongue body approach of /i/ commenced during the vocoid segment of /a/, simultaneously with the pharyngeal tongue body withdrawal of /a/ and velar tongue body approach of $/ \mathrm{k} /$. It continued through the $/ \mathrm{k} /$ occlusion, while the velar tongue body gesture of $/ \mathrm{k} /$ was being withdrawn, causing (i) the occlusion to be shifted anteriorly along the palate and (ii) the $/ \mathrm{k} /$ release to be palatalized. 


\section{Example 4: Swedish velars between palatal and nonpalatal}

\section{Articulatory profiles}

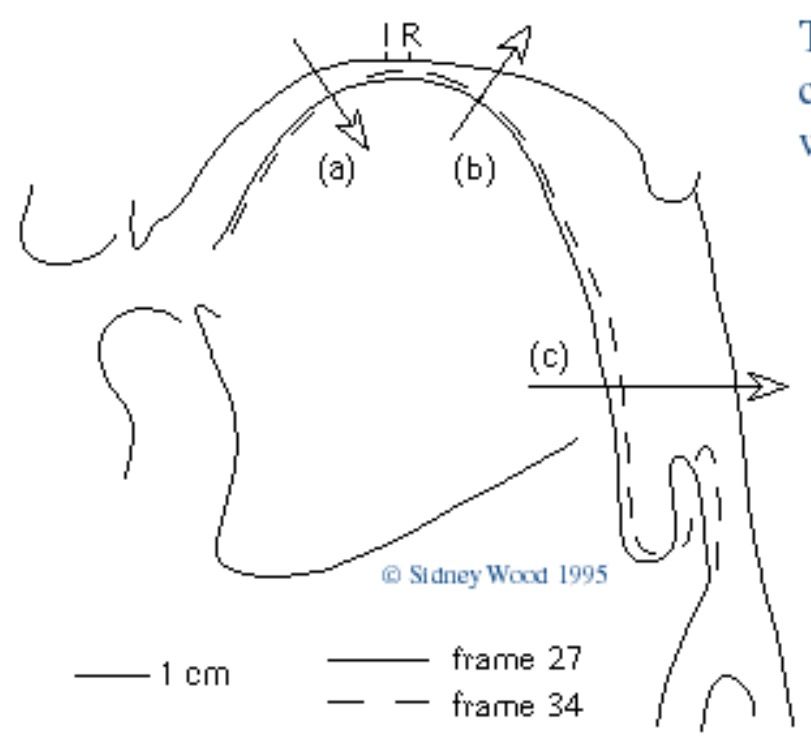

Two profiles from /k/ in /ika/ (kacki kakor), comparing the palatalized closure (frame 27) with the release (frame 34)

- Film frame 27: final frame in /i/ vocoid before $/ \mathrm{k} /$ occlusion

- Film frame 34: first frame in /a/ vocoid after $/ \mathrm{k} /$ occlusion

These are the audible parts of the speech signal closest to the silent occlusion of $/ \mathrm{k} /$

The center of the linguopalatal contact shifted posteriorly from I to $\mathrm{R}$ during the occlusion, but only slightly

During the /i/ vocoid, the palatal tongue body posture of $/ \mathrm{i} /$ was held almost until the $/ \mathrm{k} /$ closure before being withdrawn slightly (a), simultaneously with the velar tongue body approach of $/ \mathrm{k} /(\mathrm{b})$. The pharyngeal tongue body approach of $/ \mathrm{a} /$ (c) did not commence until the $/ \mathrm{k} /$ release.

The small difference between the profiles represents tongue movement during the $/ \mathrm{k} /$ occlusion due to continued palatal tongue body withdrawal of /i/ and velar tongue body approach of $/ \mathrm{k} /$. 


\title{
Swedish velars between palatal and nonpalatal (contd.)
}

\author{
Gesture coordination
}

\section{Interweaving of articulator gestures for /ika/ (in kacki kakor)}

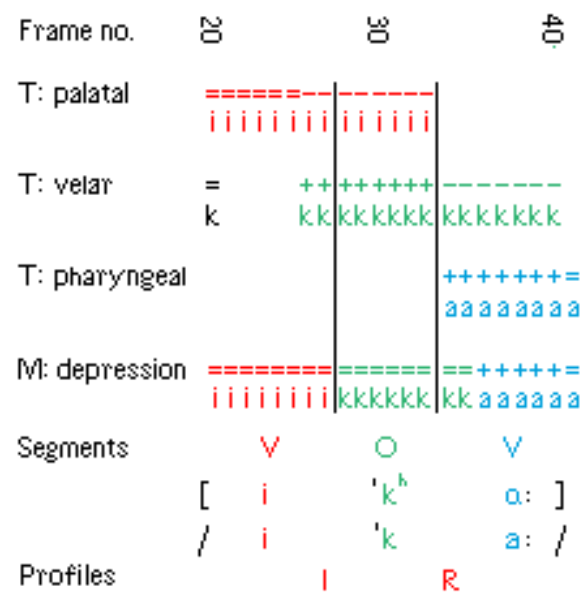

The articulator gestures are listed down the left, the film frames are numbered along the top

A row shows activity of the respective articulator. Each instance of a gesture is assigned to the phoneme the articulator happens to be busy with

A column shows all activity during the respective film frame. Coarticulation appears as simultaneous activity for different phonemes

+ Gesture approach (movement towards target)

$=$ Gesture hold (no movement)

- Gesture withdrawl (movement from target)

V Phonetic vocoid segment in sound wave

O Phonetic occlusive segment in sound wave

I Frame 27, closure of $/ \mathrm{k} /$ at end of $/ \mathrm{i} /$ vocoid

R Frame 34, release of $/ \mathrm{k} /$ at beginning of $/ \mathrm{a}: /$ vocoid

The palatal tongue body posture of /i/ was held through the latter part of the vocoid segment of $/ \mathrm{i} /$, palatalizing the closure of $/ \mathrm{k}$. The palatal tongue body gesture of $/ \mathrm{i} / \mathrm{was}$ withdrawn simultaneously with commencement of the velar tongue body approach of $/ \mathrm{k} /$. This withdrawal of $/ \mathrm{i} /$ and approach of $/ \mathrm{k} /$ continued through the $/ \mathrm{k} /$ occlusion, causing the occlusion to be shifted posteriorly along the palate from I to R, although only slightly. The pharyngeal tongue body approach of /a/ did not commence until the $/ \mathrm{k} /$ release, simultaneously with the velar tongue body withdrawal of $/ \mathrm{k} /$. 


\section{Swedish dorsovelar stops: Discussion}

Two examples of palatalized Swedish velar stops have been shown, with profiles and gesture scores for each:

- The first was an example of a fronted release (/k/ in /aki/),

- The second was an example of a fronted closure (/k/ in /ika:/).

Here again the articulator gestures were timed differently for each situation.

For the first example with the fronted release (example 3 p.13), the pharyngeal tongue body withdrawal of $/ \mathrm{a} /$, the velar tongue body approach of $/ \mathrm{k} /$ and the palatal tongue body approach of /i/ all commenced during the prestop vocoid segment of /a/. The palatal tongue body gesture of $/ \mathrm{i} /$ continued through the $/ \mathrm{k} /$ occlusion, shifting its center about $5 \mathrm{~mm}$ anteriorly and palatalizing the release.

For the second example with the fronted closure (example 4 p.15), the palatal tongue body gesture of /i/ was held almost until the end of its prestop vocoid segment, palatalizing the closure. Then the palatal tongue body withdrawal of $/ \mathrm{i} / \mathrm{and}$ the velar tongue body approach of $/ \mathrm{k} /$ commenced simultaneously just before the $/ \mathrm{k} /$ occlusion. The center of the occlusion was retracted only very slightly so that the release was almost as fronted as the closure. This is surprising considering that the post-stop vowel is the dark [a]-like allophone of $/ \mathrm{a} /$ (since /a/ is long here), but there was no tongue body movement into the pharynx for $/ \mathrm{a} /$ until after the release and during the vocoid segment of $/ \mathrm{a} /$. 


\section{Conclusions}

The timing of articulator gestures for palatalization in these two cases (Bulgarian apicoalveolar stops and Swedish dorsovelar stops) is best described as coproduction rather than feature-spreading. The gesture scores show that the palatalizing tongue body gesture remained the property of the vowel and was not passed on to the stop.

The different phasing patterns of the palatal tongue body gesture for palatalization of closures and releases point to specific gestural reorganisation for this assimilation that is different from the regular interweaving of articulator gestures for coarticulation. They are an example of assimilation as a preplanned process that applies to specific phonemes in defined situations distinct from the coarticulatory adjustments of all phoneme instantiations to their neighbours. 


\section{References}

Fant, C. G. M. 1960. The Acoustic Theory of Speech Production. The Hague: Mouton.

Fowler, C. A. 1980. Coarticulation and theories of extrinsic timing control. Journal of Phonetics 8, 113133.

Jespersen, O. 1897. Fonetik. Copenhagen: Det Schubotheske Forlag.

Öhman, S. 1966. Coartuculation in CVC utterances: spectrographic measurements. Journal of the Acoustical Society of America 39, 151-168.

Öhman, S. 1967. Numerical model of coarticulation. Journal of the Acoustical Society of America 41, 310-320.

Pettersson, T. and Wood, S. A. J. 1987. Vowel reduction in Bulgarian and its implications for theories of vowel production. Folia Linguistica 21, 261-279.

Sweet, H. 1877. Handbook of Phonetics. Oxford: Clarendon.

Wang, W. S-Y. and Fillmore, C. J. 1961. Intrinsic cues and consonant perception. Journal of Speech and Hearing Research 4, 130-136.

Wood, S. A. J. 1979. A radiographic analysis of constriction locations for vowels. Journal of Phonetics 7 , 25-43.

Wood, S. A. J. 1986. The acoustical significance of tongue, lip and larynx manoeuvres in rounded palatal vowels. Journal of the Acoustical Society of America 80, 391-401.

Wood, S. A, J. 1991. X-ray data on the temporal coordination of speech gestures. Journal of Phonetics 19, 281-292.

Wood, S. A. J. 1993. Crosslinguistic cineradiographic studies of the temporal coordination of speech gestures. Working Papers 40, 251-263; Dept. of Linguistics, University of Lund, Sweden.

Wood, S. A. J. (1994). Syllable structure and the timing of speech gestures: an analysis of speech gestures from an X-ray film of Bulgarian specch. In R. Aulenko and A-M. Korpijaako-Huuhka (eds), Proceedings of the Third Congress of the International Clinical Phonetics and Linguistics Association, pp. 191-200. Publications of the Dept. of Phonetics Vol. 39, University of Helsinki.

Wood, S. A. J. 1996. Assimilation or coarticulation? Evidence from the coordination of tongue gestures for the palatalization of Bulgarian alveolar stops. Journal of Phonetics 24, 139-164.

Wood, S. A. J. and Pettersson, T. 1988. Vowel reduction in Bulgarian: the phonetic data and model experiments. Folia Linguistica 22, 239-262. 